Check for updates

Cite this: RSC Adv., 2017, 7, 54696

\title{
Ammonia promoted barium sulfate catalyst for dehydration of lactic acid to acrylic acid $\dagger$
}

\author{
Xinli Li, ${ }^{\text {a }}$ Zhi Chen, ${ }^{a}$ Ping Cao, ${ }^{a}$ Wenjie Pu, ${ }^{\text {b }}$ Weixin Zou, ${ }^{c}$ Congming Tang (D) *a \\ and Lin Dong $\mathbb{D C}^{\mathrm{c}}$
}

The dehydration of lactic acid (LA) to acrylic acid over ammonia promoted barium sulfate was studied under various conditions. Interplanar spacing $(d)$ calculated from the enlarged (121) diffraction peak of XRD patterns with the Bragg equation is influenced by preparation conditions, which determines the acidbase properties of the prepared barium sulfate. The present work focused on the preparation conditions such as alkaline agents, $\mathrm{pH}$ values and calcination temperatures, which affected the $d$ value. It was found that aqueous ammonia was used as an alkaline agent at $\mathrm{pH}=5$ to synthesize barium sulfate with an appropriate $d$ value, which displayed an excellent catalytic performance for LA dehydration to acrylic acid. In the presence of the prepared barium sulfate with an appropriate $d$ value, the dehydration reaction of lactic acid proceeded efficiently, with 100\% lactic acid conversion and $\sim 82 \%$ acrylic acid selectivity. The unprecedented catalytic performance is due to a balance between acidic sites and basic sites existing on the surface of the prepared catalyst. The catalyst is very stable for at least $24 \mathrm{~h}$. The deactivation catalyst can be easily regenerated as it is calcined at $500{ }^{\circ} \mathrm{C}$ for $10 \mathrm{~h}$ under the air atmosphere.

Received 28th September 2017 Accepted 24th November 2017

DOI: 10.1039/c7ra10736f

rsc.li/rsc-advances
Research on AA obtained from LA via dehydration has made much progress in recent years. Hydroxyapatites offered an excellent activity for the dehydration of LA to AA, and were intensively investigated by several groups. ${ }^{35-37}$ These studies focused on regulating the acid-base properties of catalysts by controlling the preparation conditions of catalysts, and disclosing the relation between acid-base properties and activity. Modified zeolites with alkali metals were also investigated, and viewed as a class of catalytic materials with a high efficiency. ${ }^{18,22,38-42}$ Besides, oxysalt materials of alkali earth metals and rare earth metal such as $\mathrm{BaSO}_{4},{ }^{43} \mathrm{Ba}_{2} \mathrm{P}_{2} \mathrm{O}_{7},{ }^{44}$ $\mathrm{Sr}_{2} \mathrm{P}_{2} \mathrm{O}_{7}$ modified with $\mathrm{H}_{3} \mathrm{PO}_{4}$ (ref. 45) and $\mathrm{LaPO}_{4}$ (ref. 46) were also used to catalyze the dehydration of LA, and offered an excellent performance. Very recently, the work ${ }^{47}$ has investigated the formation of $\mathrm{BaSO}_{4}$ crystal defects by means of ultrasound treatment and measured the acidity density of $\mathrm{BaSO}_{4}$ crystals with different defects, which related to catalytic activity for the dehydration of LA to AA. However, the research on constructing microstructure (especially in crystal defect) of catalyst by synthesis conditions and the relation between microstructure of catalyst and activity of catalytic dehydration of LA, is very rare.

Accordingly, we tried to construct the crystal defect of $\mathrm{BaSO}_{4}$ by controlling aqueous solution acid-base property and calcination temperature in the present work, and measured the acidity density and basicity density by $\mathrm{NH}_{3}$-TPD and $\mathrm{CO}_{2}$-TPD, respectively. Based on these characterizations, we further disclosed the relationship between acid-base property of catalyst induced by crystal defects and activity.
${ }^{a}$ School of Chemistry and Chemical Engineering, Chongqing University of Technology, Chongqing 40054, PR China. E-mail: tcmtang2001@163.com

${ }^{b}$ Chemical Synthesis and Pollution Control Key Laboratory of Sichuan Province, China West Normal University, Nanchong, Sichuan, 637002, PR China

'Jiangsu Key Laboratory of Vehicle Emissions Control, Center of Modern Analysis, Nanjing University, Nanjing 210093, PR China

$\dagger$ Electronic supplementary information (ESI) available. See DOI: 10.1039/c7ra10736f 


\section{Results and discussion}

\section{Characterization}

XRD, FT-IR and EDS. Fig. 1 showed the XRD patterns of samples prepared with different methods including alkaline reagents, $\mathrm{pH}$ values and calcination temperatures. According to recent report, ${ }^{47}$ the preparation methods involved in solvents and ultrasonic treatments in synthesis of $\mathrm{BaSO}_{4}$ crystals can efficiently produce crystal defects, generating some novel properties for improving catalytic performances. Based on the enlightenment of this work, it is expected that varying preparation parameters such as alkaline reagents, $\mathrm{pH}$ values and calcination temperatures can achieve a controllable synthesis of $\mathrm{BaSO}_{4}$ crystals with some defects. According to normal XRD patterns of the prepared samples, we can clearly observe the characteristic diffraction peaks, which matched well with the standard $\mathrm{BaSO}_{4}$ sample (JCPDS 24-1035). In other words, $\mathrm{BaSO}_{4}$ samples can be easily synthesized at different preparation conditions. However, the enlarged (121) diffraction peak for these samples differed each other (see Fig. 2), suggesting that preparation conditions had an impact on fine structure of $\mathrm{BaSO}_{4}$. For example, as for alkaline reagents, the peak (121) of the sample treated with aqueous ammonia moved toward left in the biggest distance, while it remained at the standard position $\left(2 \theta=28.746^{\circ}\right)$ as the sample was treated with ethylenediamine (Fig. 2A). As for $\mathrm{pH}$ values, it was found that all samples displayed an right shift for (121) peak except for sample treated with $\mathrm{pH}=5$. For calcination temperatures, the peak (121) moved toward right gradually with an increase of calcination temperatures. According to previous work, ${ }^{47}$ the left or right shifts of the diffraction peak was attributed to the defectinduced lattice expansion or contraction, respectively. The interplanar spacing was calculated from Bragg equation, and the results were listed in Tables 1-3. According to the theory of point defects, cations escape from their normal sites in ionic crystal, become interstitial atoms and produce vacancies. ${ }^{\mathbf{4 8 , 4 9}}$ Vacancies and interstitial atoms always form in pairs, and provide sites with unbalanced electrons. The escaped cations are electropositive and act as Lewis acid, and the electronegative vacancies can donate electrons and act as basic sites. As for
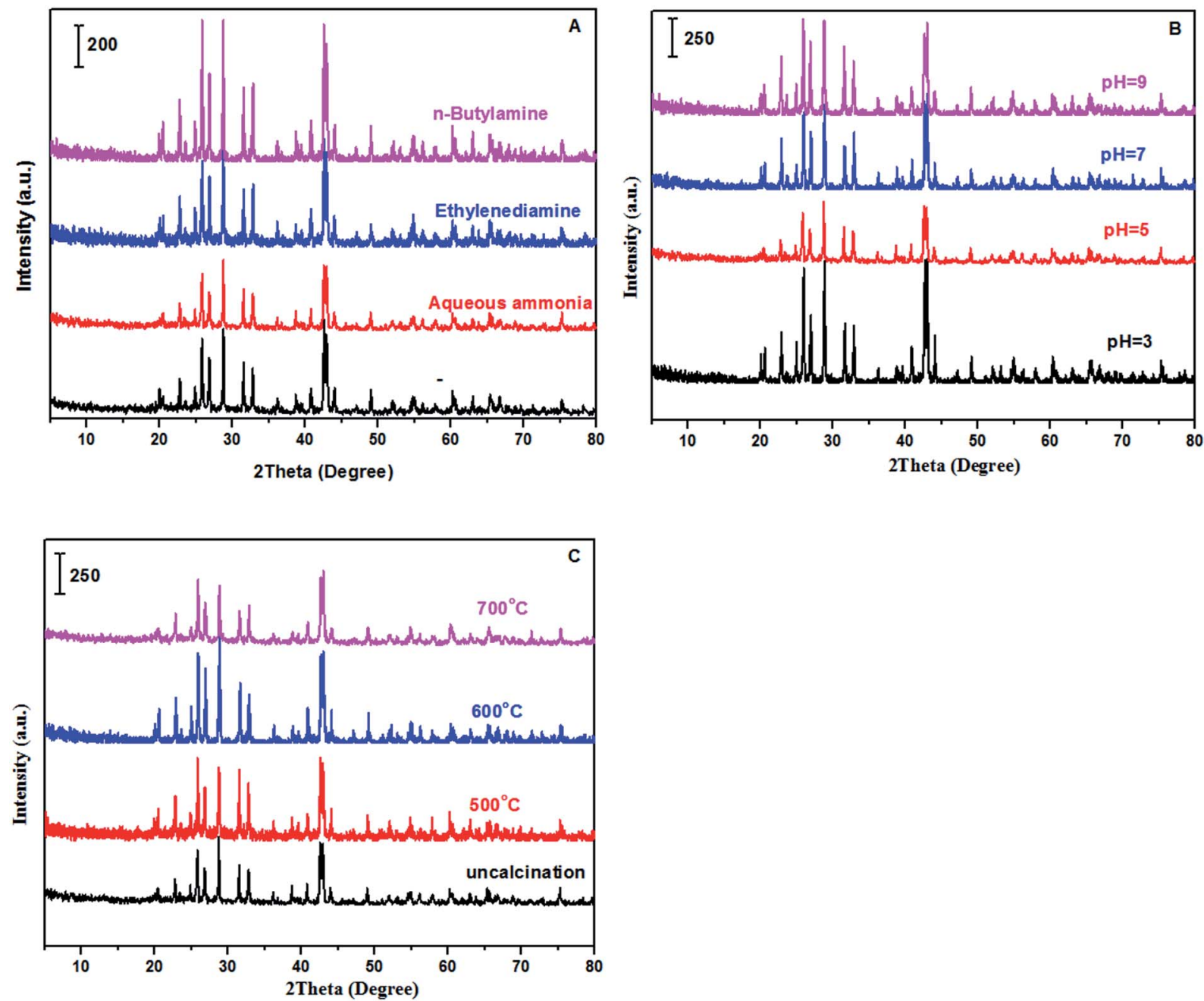

Fig. 1 XRD patterns of samples ( $\mathrm{A}$ : treated with different alkaline reagents at $\mathrm{pH}=5$; $\mathrm{B}$ : treated with aqueous ammonia at different $\mathrm{pH}$ values; and $\mathrm{C}$ : treated with aqueous ammonia and $\mathrm{pH}=5$ at different calcination temperatures). 

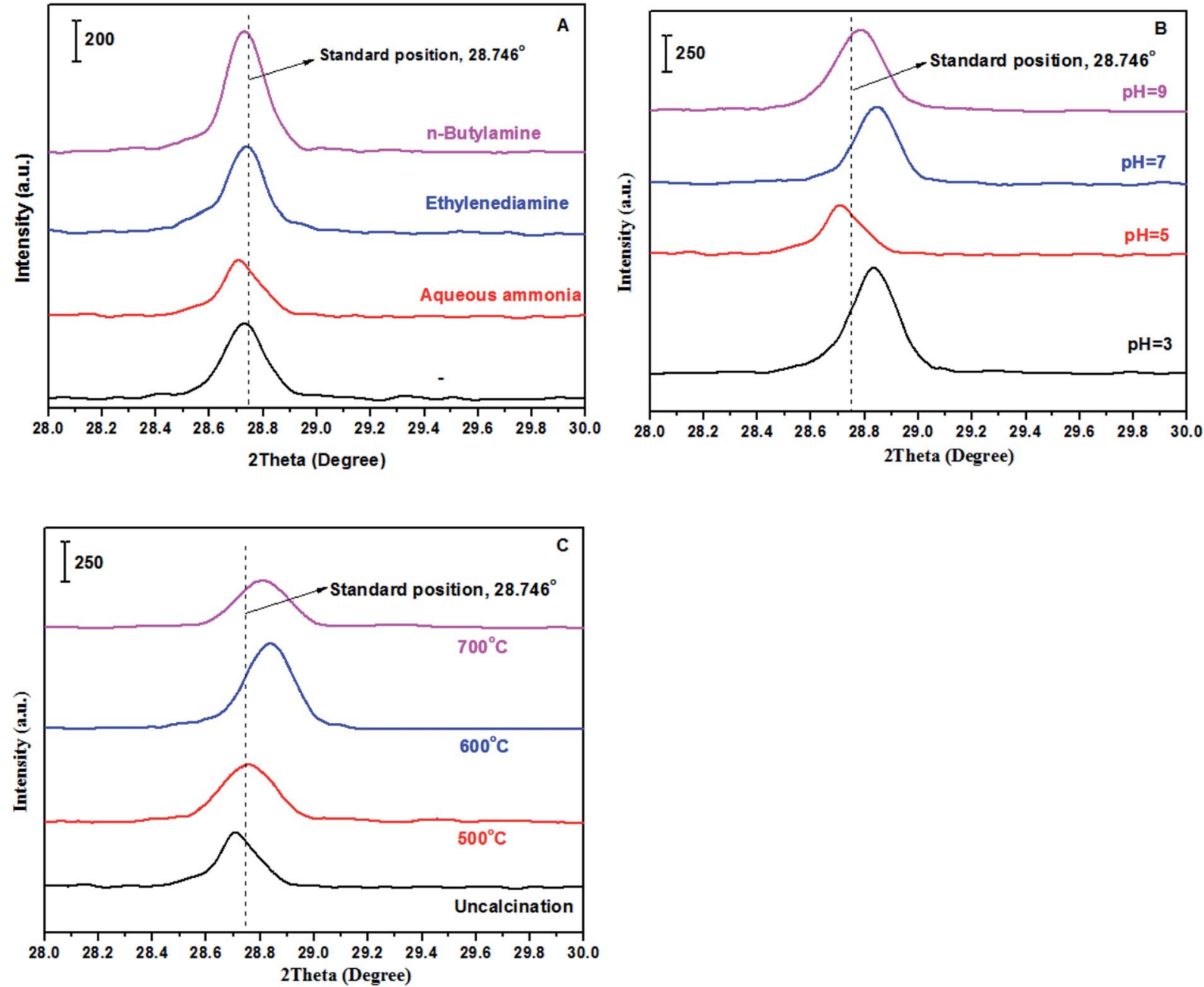

Fig. 2 The enlarged (121) diffraction peak of samples (A: treated with different alkaline reagents at $\mathrm{pH}=5$; $\mathrm{B}$ : treated with aqueous ammonia at different $\mathrm{pH}$ values; and $\mathrm{C}$ : treated with aqueous ammonia and $\mathrm{pH}=5$ at different calcination temperatures).

dehydration reaction of LA to AA, it has been confirmed that acid-base properties of catalysts play a crucial role during the catalytic process. ${ }^{17,36,37,50}$

Fig. 3 showed the FT-IR spectra of the prepared samples with different methods including alkaline reagents, $\mathrm{pH}$ values and calcination temperatures. The characteristic absorption bands occurred at $1077 \mathrm{~cm}^{-1}, 1116 \mathrm{~cm}^{-1}, 1208 \mathrm{~cm}^{-1}$, which are ascribed to $S=0$ stretching vibration; occurred at $610 \mathrm{~cm}^{-1}$ and $646 \mathrm{~cm}^{-1}$, which are ascribed to $\mathrm{O}=\mathrm{S}-\mathrm{O}$ bending mode. In addition, EDS measurement was also carried out, and showed in Fig. S1 and Table S1.† Ba, S and O elements were clearly observed in all samples, while other elements such as $\mathrm{N}$ were not observed, indicating a complete removal of impurity from samples.

Textural and acid-base properties of samples. Textural and acid-base properties of samples were measured and the results were shown in Tables 1-3 and Fig. S2-S4. $\dagger$ From the results shown in Table 1, the specific surface area of samples treated

Table 1 Textural and acid-base properties of barium sulfate treated with different alkaline reagents at $\mathrm{pH}=5$

\begin{tabular}{|c|c|c|c|c|c|c|}
\hline Alkaline reagent & $S_{\mathrm{BET}}\left(\mathrm{m}^{2} \mathrm{~g}^{-1}\right)$ & $\operatorname{Vol}\left(\mathrm{cm}^{3} \mathrm{~g}^{-1}\right)$ & 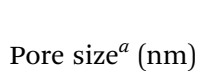 & $d^{b}(\mathrm{~nm})$ & $\begin{array}{l}\text { Surface acidity } \\
\left(\mu \mathrm{mol} \mathrm{g}{ }^{-1}\right)\end{array}$ & $\begin{array}{l}\text { Surface basicity } \\
\left(\mu \mathrm{mol} \mathrm{g}^{-1}\right)\end{array}$ \\
\hline- & 9.8 & $1.1 \times 10^{-1}$ & 3.0 & 0.3104 & 18.9 & 32.4 \\
\hline Ethylenediamine & 7.3 & $1.4 \times 10^{-1}$ & 3.4 & 0.3103 & 23.3 & 94.4 \\
\hline$n$-Butylamine & 7.4 & $1.2 \times 10^{-1}$ & 30.4 & 0.3105 & 15.2 & 90.1 \\
\hline
\end{tabular}

${ }^{a}$ Calculated from desorption branch data on the Barrett-Joyner-Halenda (BJH) model. ${ }^{b}$ Interplanar spacing, determined by enlarged (121) diffraction peak of XRD patterns with Bragg equation. 
Table 2 Textural and acid-base properties of barium sulfate treated with aqueous ammonia at different $\mathrm{pH}$ values

\begin{tabular}{|c|c|c|c|c|c|c|}
\hline $\mathrm{pH}$ value & $S_{\mathrm{BET}}\left(\mathrm{m}^{2} \mathrm{~g}^{-1}\right)$ & $\operatorname{Vol}\left(\mathrm{cm}^{3} \mathrm{~g}^{-1}\right)$ & Pore size $^{a}(\mathrm{~nm})$ & $d^{b}(\mathrm{~nm})$ & $\begin{array}{l}\text { Surface acidity } \\
\left(\mu \mathrm{mol} \mathrm{g}{ }^{-1}\right)\end{array}$ & $\begin{array}{l}\text { Surface basicity } \\
\left(\mu \mathrm{mol} \mathrm{g}{ }^{-1}\right)\end{array}$ \\
\hline- & 9.8 & $1.1 \times 10^{-1}$ & 3.0 & 0.3104 & 18.9 & 32.4 \\
\hline 5 & 8.2 & $1.1 \times 10^{-1}$ & 3.4 & 0.3107 & 15.1 & 51.2 \\
\hline 7 & 9.0 & $1.1 \times 10^{-1}$ & 3.4 & 0.3092 & 9.2 & 96.3 \\
\hline 9 & 8.9 & $1.4 \times 10^{-1}$ & 7.4 & 0.3098 & 13.0 & 57.3 \\
\hline
\end{tabular}

${ }^{a}$ Calculated from desorption branch data on the Barrett-Joyner-Halenda (BJH) model. ${ }^{b}$ Interplanar spacing, determined by enlarged (121) diffraction peak of XRD patterns with Bragg equation.

with alkaline reagents during the aging process reduced in comparison with the sample treated without alkaline reagent. Organic bases such as ethylenediamine and $n$-butylamine have a greater effect than inorganic base (aqueous ammonia) for reducing the specific surface area of sample. Interplanar spacing determined by enlarged (121) diffraction peak of XRD patterns with Bragg equation varied from 0.3103 to $0.3107 \mathrm{~nm}$, indicating that alkaline reagents can efficiently control the formation of crystal defect. Among these alkaline reagents, aqueous ammonia displayed the highest defect of crystal (corresponding $d=0.3107 \mathrm{~nm}$ ). Compared with the sample treated without alkaline reagent, all samples treated with alkaline reagents decreased in acidity except for ethylenediamine, while they all increased in basicity.

In the selected alkaline reagent of aqueous ammonia, effect of $\mathrm{pH}$ values on textural and acid-base properties of samples was shown in Table 2. Initially, the specific surface area of samples decreased with an increase of $\mathrm{pH}$ values, while it increased slightly with further increase of $\mathrm{pH}$ values. The lowest specific surface area of sample was achieved in $8.2 \mathrm{~m}^{2} \mathrm{~g}^{-1}$ as the $\mathrm{pH}$ value was adjusted to 5. It was noted that interplanar spacing determined by enlarged (121) diffraction peak of XRD patterns with Bragg equation increased compared to standard value as the $\mathrm{pH}$ value was adjusted to 5 , and others decreased. The acidity density of samples decreased with an increase of $\mathrm{pH}$ values except for $\mathrm{pH}=9$, and their corresponding basicity density varied between $32.4 \mu \mathrm{mol} \mathrm{g}^{-1}$ and $96.3 \mu \mathrm{mol} \mathrm{g}^{-1}$.

Under the fixed $\mathrm{pH}=5$ with aqueous ammonia, effect of calcination temperature on textural and acid-base properties of samples was depicted in Table 3. The specific surface area, pore volume and interplanar spacing determined by enlarged (121) diffraction peak of XRD patterns with Bragg equation of samples decreased with an increase of calcination temperature. Interestingly, the acidity density of samples also decreased with an increase of calcination temperature while their corresponding basicity density varied between $28.3 \mu \mathrm{mol} \mathrm{g}^{-1}$ and $65.4 \mu \mathrm{mol} \mathrm{g}^{-1}$.

\section{Activity}

\section{Preparation conditions of catalyst}

Alkaline reagents vs. catalytic performance. Effect of alkaline reagents on catalytic performance of the dehydration reaction of LA was investigated, and the results were shown in Table 4. Initially, we measured the activity of the catalyst treated without alkaline reagents, and the performance including LA conversion $=90.9 \%$ and AA selectivity $=59.7 \%$ was acceptable. It was expected that further improvement of catalytic performance was achieved by controlling the acid-base environment in aging process of $\mathrm{BaSO}_{4}$ crystal. It was clearly seen that all the used alkaline reagents displayed a positive effect for improving the catalytic performance except for ethylenediamine. Especially, the aqueous ammonia offered the most excellent catalytic performance (LA conversion $=100 \%$ and $\mathrm{AA}$ selectivity $=$ $81.2 \%)$. The area-specific catalytic rates were also measured, and shown in Table 4. LA consumption rate increased with using alkaline reagents, and AA formation rate occurred in increase or decrease, indicating that parallel side reactions existed. According to further observation, the selectivities to side reactions such as formation of propionic acid and acetic acid became higher, resulting in decrease of AA selectivity.

Combined with characterizations by $\mathrm{XRD}, \mathrm{NH}_{3}$-TPD and $\mathrm{CO}_{2}$-TPD, catalytic performance was found to relate to acidbase properties of $\mathrm{BaSO}_{4}$ crystals induced by microstructures. According to the measurements of interplanar spacing and acid-base properties, defects of $\mathrm{BaSO}_{4}$ crystals were produced

Table 3 Textural and acid-base properties of barium sulfate treated with aqueous ammonia and $\mathrm{pH}=5$ at different calcination temperatures

\begin{tabular}{|c|c|c|c|c|c|c|}
\hline Calc. temp. $\left({ }^{\circ} \mathrm{C}\right)$ & $S_{\mathrm{BET}}\left(\mathrm{m}^{2} \mathrm{~g}^{-1}\right)$ & $\operatorname{Vol}\left(\mathrm{cm}^{3} \mathrm{~g}^{-1}\right)$ & 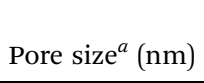 & $d^{b}(\mathrm{~nm})$ & $\begin{array}{l}\text { Surface acidity } \\
\left(\mu \mathrm{mol} \mathrm{g}{ }^{-1}\right)\end{array}$ & $\begin{array}{l}\text { Surface basicity } \\
\left(\mu \mathrm{mol} \mathrm{g}^{-1}\right)\end{array}$ \\
\hline - & 8.2 & $1.1 \times 10^{-1}$ & 3.4 & 0.3107 & 15.1 & 51.2 \\
\hline 600 & 4.1 & $9.5 \times 10^{-2}$ & 6.9 & 0.3093 & 8.4 & 28.3 \\
\hline 700 & 3.7 & $2.6 \times 10^{-2}$ & 3.4 & 0.3096 & 3.7 & 56.1 \\
\hline
\end{tabular}

${ }^{a}$ Calculated from desorption branch data on the Barrett-Joyner-Halenda (BJH) model. ${ }^{b}$ Interplanar spacing, determined by enlarged (121) diffraction peak of XRD patterns with Bragg equation. 

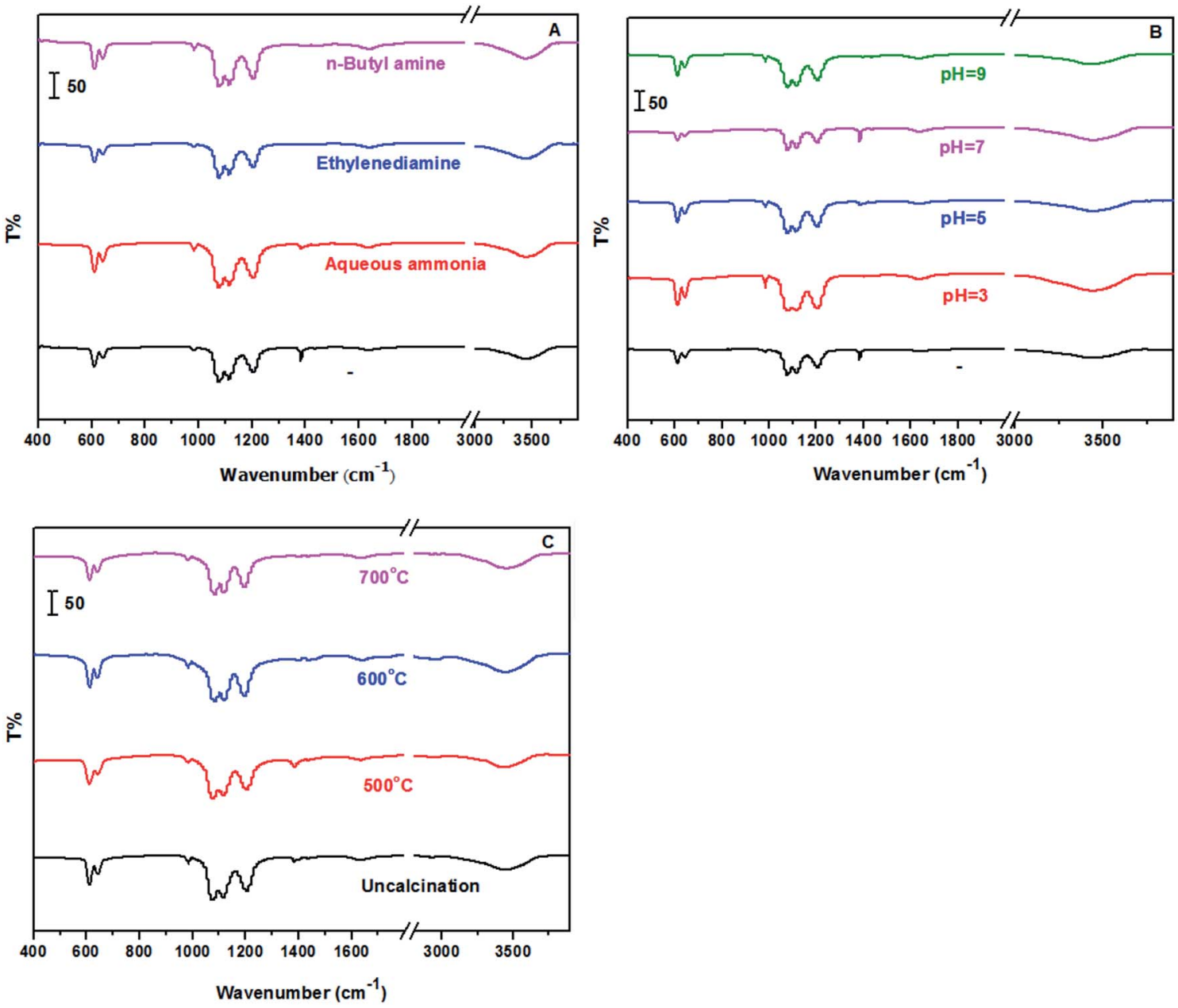

Fig. 3 FT-IR spectra of samples ( $\mathrm{A}$ : treated with different alkaline reagents at $\mathrm{pH}=5$; $\mathrm{B}$ : treated with aqueous ammonia at different $\mathrm{pH}$ values; and $\mathrm{C}$ : treated with aqueous ammonia and $\mathrm{pH}=5$ at different calcination temperatures).

by deviation of interplanar spacing to normal value, and caused different acid-base properties. Pioneering work has demonstrated that acid-base properties of catalysts are crucial to catalytic dehydration of LA to AA. ${ }^{17,22,36,37}$ Recently, the work has disclosed that both ultrasound treatment and aging time can efficiently control the formation of crystal defects, which result in different acidity. ${ }^{47}$ In the present work, alkaline reagents were used to control the acid-base environment of aqueous solution in which crystal formed and grew, and we observed the formation of crystal defects. Due to the crystal defects, the $\mathrm{BaSO}_{4}$ crystals treated with different alkaline reagents offered different acid-base properties. From the results shown in Table 4, catalytic performance decreased with an increase of acidity density; and it was also affected by basicity, and medium basicity density favored the catalytic performance for dehydration of LA to AA. For example, ethylenediamine treated sample displayed the

Table 4 Effect of alkaline reagents on catalytic performance of the dehydration reaction of $\mathrm{LA}^{a}$

\begin{tabular}{|c|c|c|c|c|c|c|c|c|c|}
\hline \multirow[b]{2}{*}{ Alkaline reagents } & \multirow[b]{2}{*}{$\begin{array}{l}\text { LA conv. } \\
{[\%]}\end{array}$} & \multicolumn{5}{|c|}{ Sel. $^{b}[\%]$} & \multirow[b]{2}{*}{$\begin{array}{l}\text { Carbon balance } \\
{[\%]}\end{array}$} & \multicolumn{2}{|c|}{$\begin{array}{l}\text { Area-specific catalytic rate } \\
\left(\mu \mathrm{mol} \mathrm{h}{ }^{-1} \mathrm{~m}^{-2}\right)\end{array}$} \\
\hline & & $\mathrm{AA}$ & $\mathrm{AD}$ & PA & $\mathrm{AC}$ & $\mathrm{PD}$ & & LA consumption & AA formation \\
\hline- & 90.9 & 59.7 & 16.7 & 17.1 & 1.8 & 1.4 & 93.6 & 601 & 359 \\
\hline Aqueous ammonia & 100 & 81.2 & 12.1 & 4.5 & 1.3 & 0.3 & 99.6 & 759 & 616 \\
\hline Ethylenediamine & 89.1 & 48.6 & 21.1 & 23.1 & 4.8 & 1.0 & 89.3 & 678 & 330 \\
\hline$n$-Butylamine & 99.5 & 69.1 & 20.9 & 7.1 & 1.6 & 0.6 & 99.7 & 709 & 490 \\
\hline
\end{tabular}

${ }^{a}$ Catalyst, $0.38 \mathrm{~mL}, 0.48-0.59 \mathrm{~g}$, uncalcination, particle size: $20-40$ meshes, carrier gas $\mathrm{N}_{2}: 1.2 \mathrm{~mL} \mathrm{~min}^{-1}$, feed flow rate: $1.4 \mathrm{~mL} \mathrm{~h}{ }^{-1}$, LA feedstock: $20 \mathrm{wt} \%$ in water, reaction temperature, $400{ }^{\circ} \mathrm{C}$, TOS: $2-4 \mathrm{~h} .{ }^{b}$ LA: lactic acid, AA: acrylic acid, AD: acetaldehyde, PA: propionic acid, AC: acetic acid, PD: 2,3-pentanedione. 
Table 5 Effect of $\mathrm{pH}$ values modulated with aqueous ammonia on catalytic performance of the dehydration reaction of $\mathrm{LA}^{a}$

\begin{tabular}{|c|c|c|c|c|c|c|c|c|c|}
\hline \multirow[b]{2}{*}{$\mathrm{pH}$} & \multirow{2}{*}{$\begin{array}{l}\text { LA conv. } \\
{[\%]}\end{array}$} & \multicolumn{5}{|c|}{ Sel. $^{b}[\%]$} & \multirow[b]{2}{*}{ Carbon balance } & \multicolumn{2}{|c|}{$\begin{array}{l}\text { Area-specific catalytic rate } \\
\left(\mu \mathrm{mol} \mathrm{h}{ }^{-1} \mathrm{~m}^{-2}\right)\end{array}$} \\
\hline & & AA & $\mathrm{AD}$ & PA & $\mathrm{AC}$ & $\mathrm{PD}$ & & LA consumption & AA formation \\
\hline - & 90.9 & 59.7 & 16.7 & 17.1 & 1.8 & 1.4 & 93.6 & 601 & 359 \\
\hline 3 & 82.5 & 60.4 & 22.1 & 13.1 & 2.5 & 0.5 & 82.7 & 491 & 297 \\
\hline 5 & 100 & 81.2 & 12.1 & 4.5 & 1.3 & 0.3 & 99.6 & 759 & 616 \\
\hline 7 & 92.5 & 67.8 & 22.0 & 7.5 & 1.5 & 0.9 & 84.9 & 615 & 417 \\
\hline 9 & 97.5 & 69.7 & 17.5 & 9.4 & 1.6 & 1.2 & 100 & 668 & 466 \\
\hline
\end{tabular}

${ }^{a}$ Catalyst, $0.38 \mathrm{~mL}, 0.48-0.55 \mathrm{~g}$, uncalcination, particle size: $20-40$ meshes, carrier gas $\mathrm{N}_{2}: 1.2 \mathrm{~mL} \mathrm{~min}^{-1}$, feed flow rate: $1.4 \mathrm{~mL} \mathrm{~h}{ }^{-1}$, LA feedstock: $20 \mathrm{wt} \%$ in water, reaction temperature, $400{ }^{\circ} \mathrm{C}$, TOS: $2-4 \mathrm{~h} .{ }^{b}$ LA: lactic acid, AA: acrylic acid, AD: acetaldehyde, PA: propionic acid, AC: acetic acid, PD: 2,3-pentanedione.

poorest activity (LA conversion $=89.1 \%$ and AA selectivity $=$ $48.6 \%)$ due to the highest acidity density $\left(23.3 \mu \mathrm{mol} \mathrm{g}^{-1}\right)$. Under the identical acidity conditions, aqueous ammonia treated sample has lower basicity density $\left(51.2 \mu \mathrm{mol} \mathrm{g}^{-1}\right)$ than $n$ butylamine $\left(90.1 \mu \mathrm{mol} \mathrm{g}^{-1}\right)$, while the former offered higher selectivity of AA $(81.2 \%)$ than the latter $(69.1 \%)$ although LA conversion was close to each other.

pH values vs. catalytic performance. In the screening of alkaline reagents, aqueous ammonia was the most excellent alkaline reagent for improving the catalytic performance. The $\mathrm{pH}$ values were adjusted using aqueous ammonia to observe effect of $\mathrm{pH}$ values on catalytic performance, and the results were shown in Table 5. From the results shown in Table 5, the selectivity to AA on the catalysts treated with aqueous ammonia in the range of $\mathrm{pH}=3-5$ has been improved in comparison with the catalyst treated without any alkaline reagent. Conspicuously, the selectivity to AA achieved as high as $81.2 \%$ when $\mathrm{pH}$ value was adjusted to 5 using aqueous ammonia. It was noted that the characteristic diffraction peak of crystal face (121) moved toward left direction from the standard position $(2 \theta=$ $28.746^{\circ}$ ) with aqueous ammonia adjusting to $\mathrm{pH}=5$, while others with $\mathrm{pH}=3,7$ and 9 moved toward right direction. Lyu and Wang also observed the characteristic diffraction peak crystal face (121) moved toward right direction as the $\mathrm{BaSO}_{4}$ crystals were treated with ultrasound means. ${ }^{47}$ Whether the characteristic diffraction peak of crystal face (121) moved toward left or right direction, these $\mathrm{BaSO}_{4}$ crystals produced defects, leading to different acid-base properties located on the catalyst surface. Compared with two catalysts treated with $\mathrm{pH}=$ 3 and 9, respectively, they have similar basic site densities (56.3 $\mu \mathrm{mol} \mathrm{g}{ }^{-1}$ and $57.3 \mu \mathrm{mol} \mathrm{g}^{-1}$ ), and different acidic site densities (18.8 $\mu \mathrm{mol} \mathrm{g}{ }^{-1}$ and $\left.13.0 \mu \mathrm{mol} \mathrm{g}^{-1}\right)$. Whereas, the latter had better catalytic performance (LA conversion $=97.5 \%$ and $\mathrm{AA}$ selectivity $=69.7 \%$ ) than the former (LA conversion $=82.5 \%$ and AA selectivity $=60.4 \%$ ), indicating that appropriately lowering acidic site density favored the catalytic dehydration reaction of LA to AA.

Calcination temperature vs. catalytic performance. Table 6 showed effect of calcination temperature on the performance of catalysts. LA conversion decreased from $100 \%$ to $50.1 \%$ as the calcination temperature increased from uncalcination to $600{ }^{\circ} \mathrm{C}$. With further increase of calcination temperature to $700{ }^{\circ} \mathrm{C}$, LA conversion began to increase to $75.9 \%$. Besides, AA selectivity also reduced with an increase of calcination temperature. Although area-specific catalytic rate (LA consumption: $1227 \mu \mathrm{mol} \mathrm{h}{ }^{-1} \mathrm{~m}^{-2}$ and AA formation: $724 \mu \mathrm{mol}$ $\mathrm{h}^{-1} \mathrm{~m}^{-2}$ ) on the catalyst calcined at $700{ }^{\circ} \mathrm{C}$ was the highest among all the catalysts calcined at different temperatures ( $c a$. $\sim 700{ }^{\circ} \mathrm{C}$ ), LA conversion as well as AA selectivity is relatively lower due to its low specific surface area (only $3.7 \mathrm{~m}^{2} \mathrm{~g}^{-1}$ far lower than others $\left.\left(\sim 8 \mathrm{~m}^{2} \mathrm{~g}^{-1}\right)\right)$. In order to better understand the effect of calcination temperature on the catalytic performance, we can draw support from the XRD characterization shown in Fig. $2 \mathrm{C}$ and the acid-base site density shown in Table 3. With an increase of calcination temperature, characteristic diffraction peak of crystal face (121) also gradually moved

Table 6 Effect of calcination temperature on catalytic performance of the dehydration reaction of $\mathrm{LA}^{a}$

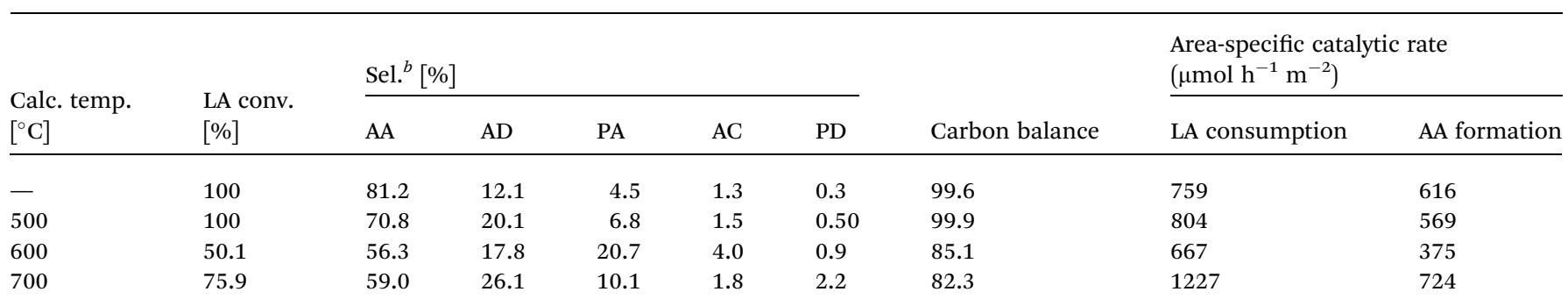

${ }^{a}$ Catalyst, $0.38 \mathrm{~mL}, 0.45-0.57 \mathrm{~g}$, particle size: $20-40$ meshes, carrier gas $\mathrm{N}_{2}: 1.2 \mathrm{~mL} \mathrm{~min}^{-1}$, feed flow rate: $1.4 \mathrm{~mL} \mathrm{~h}{ }^{-1}$, $\mathrm{LA}$ feedstock: $20 \mathrm{wt} \%$ in water, reaction temperature, $400{ }^{\circ} \mathrm{C}$, TOS: $2-4$ h. ${ }^{b}$ LA: lactic acid, AA: acrylic acid, AD: acetaldehyde, PA: propionic acid, AC: acetic acid, PD: $2,3-$ pentanedione. 
Table 7 Effect of reaction temperature on performance of the dehydration reaction of $\mathrm{LA}^{a}$

\begin{tabular}{|c|c|c|c|c|c|c|c|c|c|}
\hline \multirow{2}{*}{$\begin{array}{l}\text { Reaction temp. } \\
{\left[{ }^{\circ} \mathrm{C}\right]}\end{array}$} & \multirow{2}{*}{$\begin{array}{l}\text { LA conv. } \\
{[\%]}\end{array}$} & \multicolumn{5}{|c|}{ Sel. $^{b}[\%]$} & \multirow[b]{2}{*}{ Carbon balance } & \multicolumn{2}{|c|}{$\begin{array}{l}\text { Area-specific catalytic rate } \\
\left(\mu \mathrm{mol} \mathrm{h}{ }^{-1} \mathrm{~m}^{-2}\right)\end{array}$} \\
\hline & & AA & $\mathrm{AD}$ & PA & $\mathrm{AC}$ & PD & & LA consumption & AA formation \\
\hline 350 & 69.7 & 82.1 & 9.2 & 4.5 & 0.9 & 0.2 & 95.5 & 499 & 410 \\
\hline 370 & 98.5 & 81.7 & 10.9 & 4.8 & 1.1 & 0.2 & 99.8 & 705 & 576 \\
\hline 400 & 100 & 81.2 & 12.1 & 4.5 & 1.3 & 0.3 & 99.6 & 759 & 616 \\
\hline
\end{tabular}

${ }^{a}$ Catalyst, $0.38 \mathrm{~mL}, 0.49-0.53 \mathrm{~g}$, uncalcination, particle size: $20-40$ meshes, carrier gas $\mathrm{N}_{2}: 1.2 \mathrm{~mL} \mathrm{~min}^{-1}$, feed flow rate: $1.4 \mathrm{~mL} \mathrm{~h}{ }^{-1}$, LA feedstock: $20 \mathrm{wt} \%$ in water, TOS: $2-4 \mathrm{~h} .{ }^{b}$ LA: lactic acid, AA: acrylic acid, AD: acetaldehyde, PA: propionic acid, AC: acetic acid, PD: 2,3-pentanedione.

toward right direction, suggesting that high temperature favored the formation of crystal defects. As a result, different acid-base properties of catalysts were achieved by calcination.

Furthermore, we correlated the catalytic performance of catalysts with acid-base properties of catalysts. Firstly, we compared the catalyst without calcination with the catalyst calcined at $700{ }^{\circ} \mathrm{C}$, and found that they had similar basic site density $\left(51.2 \mu \mathrm{mol} \mathrm{g}^{-1}\right.$ and $\left.56.1 \mu \mathrm{mol} \mathrm{g}^{-1}\right)$, and different acidic site density $\left(15.1 \mu \mathrm{mol} \mathrm{g}{ }^{-1}\right.$ vs. $\left.3.7 \mu \mathrm{mol} \mathrm{g}{ }^{-1}\right)$. The catalytic performance of the former (LA conversion $=100 \%$ and $\mathrm{AA}$ selectivity $=82.1 \%$ ) was obviously more excellent than the latter (LA conversion $=75.9 \%$ and AA selectivity $=59.0 \%$ ), suggesting that too low acidic site density was unfavourable for the dehydration of LA to AA. The poorest performance (LA conversion = $50.1 \%$ and AA selectivity $=56.3 \%$ ) was observed over the catalyst calcined at $600{ }^{\circ} \mathrm{C}$, indicating that too low basic site density had also a disadvantage for the dehydration of LA to AA.

\section{Reaction conditions}

Reaction temperature vs. reaction performance. According to the discussion on preparation conditions of catalysts in the preceding sections, we obtained the optimal preparation conditions for $\mathrm{BaSO}_{4}$ with crystal defects (alkaline reagent: aqueous ammonia, $\mathrm{pH}=5$.). Next, effect of reaction conditions on the dehydration of LA would be investigated. As an important factor determining the reaction rate and reaction selectivity, reaction temperature was firstly discussed. ${ }^{51}$ From effect of reaction temperature on dehydration of LA shown in Table 7, LA conversion increased with an increase of reaction temperature from $350{ }^{\circ} \mathrm{C}$ to $400{ }^{\circ} \mathrm{C}$. For a given catalyst, area-specific catalytic rate also increased with an increase of reaction temperature. For this reason, LA conversion increased with an increase of reaction temperature. However, as the reaction temperature was above $400{ }^{\circ} \mathrm{C}$, LA conversion remained constant (100\%). As for AA selectivity, it gradually decreased with an increase of reaction temperature while byproduct selectivity increased, indicating that the side reactions were accelerated at higher reaction temperature. For example, propionic acid selectivity and acetic acid selectivity achieved $13.2 \%$ and $4.1 \%$, respectively, far higher than those obtained at $350{ }^{\circ} \mathrm{C}$ $(4.5 \%$ and $0.9 \%)$.

Catalyst colour became darker with an increase of reaction temperature, and displayed a black colour especially at $440{ }^{\circ} \mathrm{C}$

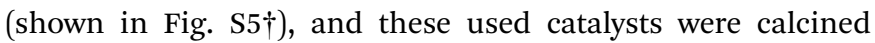
under the air atmosphere at $500{ }^{\circ} \mathrm{C}$ for $10 \mathrm{~h}$ to obtain light colour again, suggesting that the substance formed on the catalyst surface may be carbon or coke, which covered the active sites, leading to decrease of AA selectivity.

Weight hourly space velocity (WHSV) vs. reaction performance. Weight hourly space velocity (WHSV) is generally used to evaluate the performance of heterogeneous catalyst. ${ }^{52,53}$ Table 8 showed the influence of LA WHSV on reaction performance. The reaction was conducted at $400{ }^{\circ} \mathrm{C}$ with LA flow rate changed from 1.0 to $8.4 \mathrm{~mL} \mathrm{~h}^{-1}$ (corresponding WHSV $=2.0-16.8 \mathrm{~h}^{-1}$ ). For LA conversion, it almost remained at $100 \%$ when LA WHSV was lower than $2.8 \mathrm{~h}^{-1}$. As LA WHSV increased from $2.8 \mathrm{~h}^{-1}$ to $16.8 \mathrm{~h}^{-1}$, LA conversion gradually decreased from $100 \%$ to $70.5 \%$. AA selectivity, unlike LA conversion, increased fast from $71.3 \%$ to $81.2 \%$ with an increase of LA WHSV from $2.0 \mathrm{~h}^{-1}$ to 2.8

Table 8 Effect of weight hourly space velocity (WHSV) on performance of the dehydration reaction of $\mathrm{LA}^{a}$

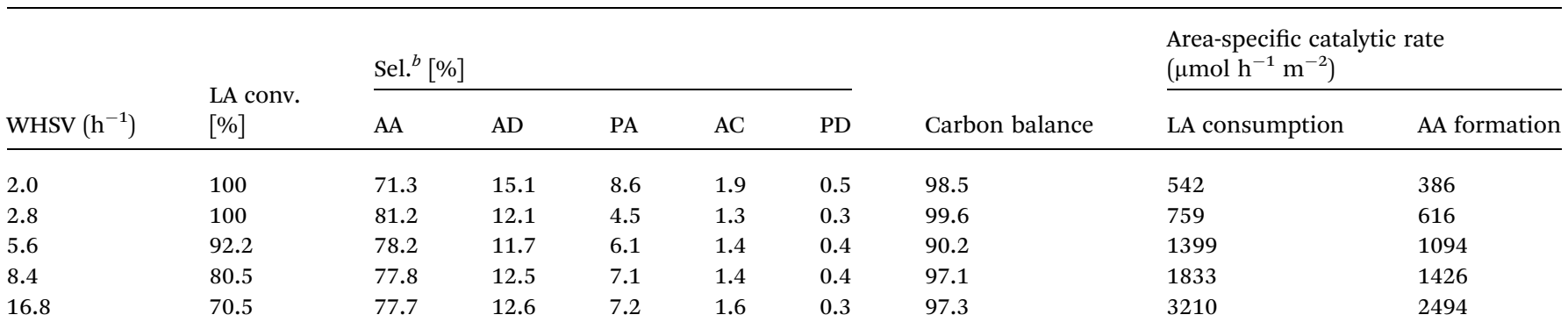

${ }^{a}$ Catalyst, $0.38 \mathrm{~mL}, 0.5 \mathrm{~g}$, uncalcination, particle size: $20-40$ meshes, carrier gas $\mathrm{N}_{2}: 1.2 \mathrm{~mL} \mathrm{~min}{ }^{-1}$, LA feedstock: $20 \mathrm{wt} \%$ in water, reaction temperature, $400{ }^{\circ} \mathrm{C}$, TOS: $2-4$ h. ${ }^{b}$ LA: lactic acid, AA: acrylic acid, AD: acetaldehyde, PA: propionic acid, AC: acetic acid, PD: 2,3-pentanedione. 


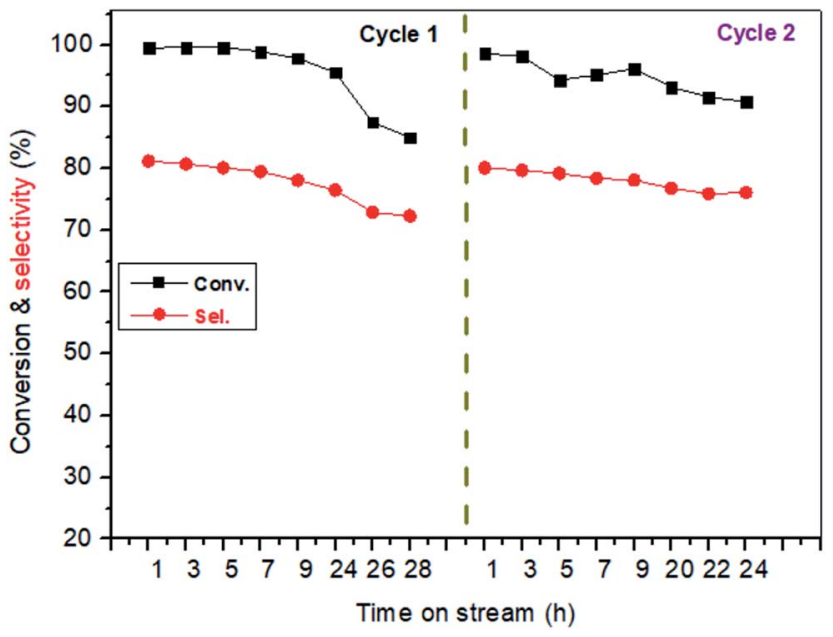

Fig. 4 The stability of catalyst with time on stream. Catalyst, $0.38 \mathrm{~mL}$, $0.5 \mathrm{~g}$, uncalcination, particle size: $20-40$ meshes, carrier gas $\mathrm{N}_{2}: 1.2$ $\mathrm{mL} \mathrm{min}^{-1}$, feed flow rate: $1.4 \mathrm{~mL} \mathrm{~h}^{-1}$, LA feedstock: 20 wt\% in water, reaction temperature, $400{ }^{\circ} \mathrm{C}$. The used catalyst in cycle 1 was calcined at $500{ }^{\circ} \mathrm{C}$ for $10 \mathrm{~h}$ to remove the carbon deposits from its surface, and then was used again in cycle 2 .

$\mathrm{h}^{-1}$. It is known that LA contact time on the surface of $\mathrm{BaSO}_{4}$ catalyst shortens with the enhancement of LA WHSV. ${ }^{28}$ The appropriately shortened contact time favored the selective formation of $\mathrm{AA}$, indicating that dehydration reaction of $\mathrm{LA}$ is relatively faster than other side reactions. Area-specific catalytic rate quickly increased with an increase of LA solution WHSV. For example, LA consumption rate was $542 \mu \mathrm{mol} \mathrm{h}^{-1} \mathrm{~m}^{-2}$ at LA solution WHSV $=2.0 \mathrm{~h}^{-1}$ while it attained to $3210 \mu \mathrm{mol} \mathrm{h} \mathrm{h}^{-1}$ $\mathrm{m}^{-2}$ at LA solution WHSV $=16.8 \mathrm{~h}^{-1}$. For that reason, $70.5 \%$ of LA conversion was obtained at high WHSV of $16.8 \mathrm{~h}^{-1}$.

Stability of catalyst. Fig. 4 showed the stability of the catalyst with time on stream. The experiment was performed at $400{ }^{\circ} \mathrm{C}$ with LA concentration of $20 \mathrm{wt} \%$ and feed flow rate of $1.4 \mathrm{~mL}$ $\mathrm{h}^{-1}$. It is known that long-term stability is a very important characteristic for a heterogeneous catalyst. ${ }^{54}$ From the cycle 1 of

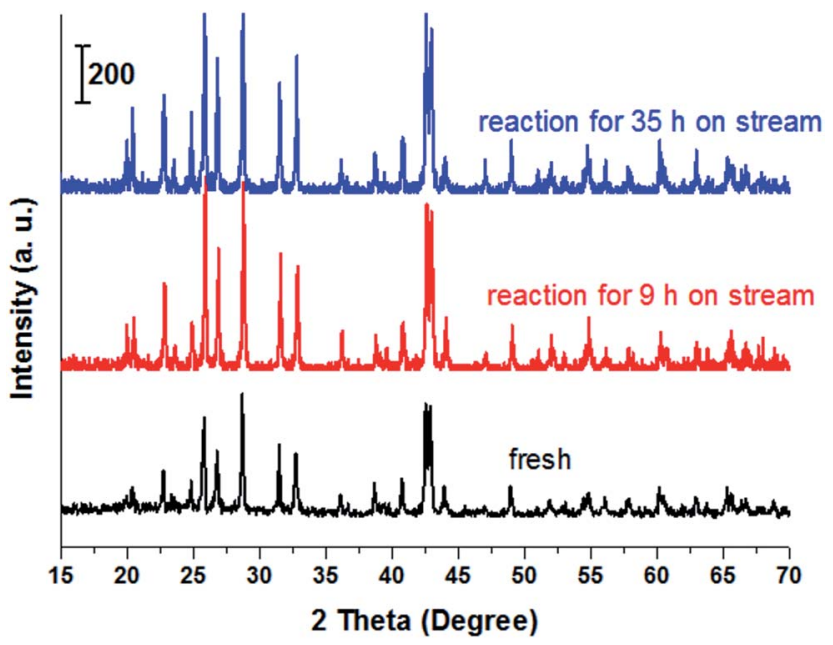

Fig. 5 XRD patterns of fresh $\mathrm{BaSO}_{4}$ catalyst and spent $\mathrm{BaSO}_{4}$ catalysts.
Fig. 4, LA conversion slightly decreased within initial $24 \mathrm{~h}$ on stream while after experienced $24 \mathrm{~h}$ on stream, LA conversion drastically reduced to near $85 \%$. Similarly, AA selectivity was influenced by the time on stream. For example, AA selectivity also slightly decreased from about $81.2 \%$ to $76.5 \%$ within the initial reaction time (1-24 h). Catalytic performance reduced with time on stream, indicating a deactivation of catalyst. However, the deactivated catalyst can be easily regenerated after a simple calcination at $500{ }^{\circ} \mathrm{C}$ for $10 \mathrm{~h}$ under the air atmosphere because the resultants on the catalyst surface causing in deactivation are carbon or coke (also shown in Fig. 4, cycle 2). In addition, XRD, FT-IR and TG characterizations of the spent catalyst and the fresh catalyst was performed, and the results were shown in Fig. 5, S6 and S7. $\uparrow$ It was clearly seen that the structure of $\mathrm{BaSO}_{4}$ crystal remained well during the catalytic reaction.

\section{Experimental}

\section{Materials}

Lactic acid (85-90 wt\%), was purchased from Chengdu Kelong Chemical Reagent Co. and was used for the dehydration reaction of lactic acid to synthesize AA without further purification. Sulphuric acid $\left(\mathrm{H}_{2} \mathrm{SO}_{4}\right)$, barium hydroxide $\left(\mathrm{Ba}(\mathrm{OH})_{2}\right)$, aqueous ammonia, $n$-butylamine, and ethylenediamine were purchased from Energy Chemical Company. Acrylic acid, propionic acid, acetic acid, acetaldehyde, 2,3-pentanedione and $n$-butanol, together with hydroquinone were obtained from Sigma-Aldrich. Acrylic acid, propionic acid, acetic acid, 2,3-pentanedione and acetaldehyde were used for gas chromatograph reference materials, and $n$-butanol was adopted as internal standard material. Hydroquinone $(0.3 \mathrm{wt} \%$ ) was used as a polymerization inhibitor.

\section{Preparation of catalysts}

$\mathrm{BaSO}_{4}$ catalyst (blank): firstly, $25.20 \mathrm{~g}$ of $\mathrm{Ba}(\mathrm{OH})_{2}$ was fully dissolved in $150 \mathrm{~mL}$ distilled water. Under stirring at room temperature, diluted $\mathrm{H}_{2} \mathrm{SO}_{4}$ solution with 0.2 mol $\mathrm{L}^{-1}$ was dropwisely added to the obtained $\mathrm{Ba}(\mathrm{OH})_{2}$ aqueous solution to form a white precipitate of barium sulfate at $\mathrm{pH}=2$, and aged for $15 \mathrm{~h}$. Subsequently, the white precipitate was rinsed at least three times to remove dissociative $\mathrm{H}_{2} \mathrm{SO}_{4}$ using distilled water and dried at $120{ }^{\circ} \mathrm{C}$ in the air circulating oven for $3 \mathrm{~h}$.

$\mathrm{BaSO}_{4}$ catalyst treated with alkaline agents: the obtained $\mathrm{BaSO}_{4}$ precipitates with above preparation method were aged for $15 \mathrm{~h}$ at $\mathrm{pH}=5$ using different alkaline agents. Specially, using aqueous ammonia to adjust $\mathrm{pH}$ values, $\mathrm{BaSO}_{4}$ precipitates were aged at $\mathrm{pH}=3,7$, and 9 for $15 \mathrm{~h}$, respectively.

\section{Catalyst characterization}

Powder X-ray diffraction measurement was conducted on a Dmax/Ultima IV diffractometer operated at $40 \mathrm{kV}$ and $20 \mathrm{~mA}$ with $\mathrm{Cu}-\mathrm{K} \alpha$ radiation. The FTIR spectra of the catalysts were recorded in the range of $500-4000 \mathrm{~cm}^{-1}$ on a Nicolet $6700 \mathrm{spec}-$ trometer. The EDS measurements of the catalysts were performed using a scanning electron microscope (SEM, JSM-6510). The specific surface areas of catalysts were measured through nitrogen adsorption at $77 \mathrm{~K}$ using Autosorb IQ instrument. Prior 
to adsorption, the samples were treated at $250{ }^{\circ} \mathrm{C}$ under vacuum for $6 \mathrm{~h}$ and the specific surface area was calculated according to the Brunauer-Emmett-Teller (BET) method. Surface acid and base properties of the samples were estimated by $\mathrm{NH}_{3}$-TPD and $\mathrm{CO}_{2}$-TPD, respectively, on a Quantachrome Instrument. The sample (ca. 50-60 mg) was purged with dry $\operatorname{Ar}\left(50 \mathrm{~mL} \mathrm{~min}{ }^{-1}\right.$, purity $>99.999 \mathrm{vol} \%$ ) at $400{ }^{\circ} \mathrm{C}$ for $1.0 \mathrm{~h}$, followed by reducing the furnace temperature to room temperature, and switching to a flow of $8 \mathrm{vol} \% \mathrm{NH}_{3} / \mathrm{Ar}$ or $10 \mathrm{vol} \% \mathrm{CO}_{2} / \mathrm{Ar}$ for $1 \mathrm{~h}$ to execute $\mathrm{NH}_{3}$ or $\mathrm{CO}_{2}$ adsorption. Then, $\mathrm{NH}_{3}$ or $\mathrm{CO}_{2}$ adsorbed on the sample is desorbed in the range of $80-800{ }^{\circ} \mathrm{C}$ at a rate of $10{ }^{\circ} \mathrm{C} \mathrm{min}^{-1}$.

\section{Catalyst evaluation}

The vapor-phase dehydration reaction of lactic acid to acrylic acid over the catalysts was carried out at $350-440{ }^{\circ} \mathrm{C}$ under atmospheric pressure in a vertical fixed-bed tubular quartz reactor $(40 \mathrm{~cm} \times 4 \mathrm{~mm}$ (i.d.)), mounted in a cylindrical electrical furnace. The catalyst $(0.50-0.60 \mathrm{~g}, 20-40$ meshes $)$ was placed in the middle of the reactor and quartz wool was placed in both ends. Before catalyst evaluation, the catalyst was pretreated at the required reaction temperature $\left(\mathrm{ca} .400{ }^{\circ} \mathrm{C}\right)$ for 1.0 $\mathrm{h}$ under high purity $\mathrm{N}_{2}\left(0.1 \mathrm{MPa}, 1.2 \mathrm{~mL} \mathrm{~min}^{-1}\right)$. The feedstock ( $20 \mathrm{wt} \%$ solution of lactic acid) was then pumped into the preheating zone (lactic acid aqueous solution flow rate, $1.4 \mathrm{~mL}$ $\mathrm{h}^{-1}$ ) and driven through the catalyst bed by nitrogen. The liquid products were condensed using ice-water bath and analyzed offline using a SP-6890 gas chromatograph with a FFAP capillary column connected to a FID. Quantitative analysis of the products was carried out by the internal standard method using $n$ butanol as the internal standard material. GC-MS analyses of the samples were performed using Agilent 5973N Mass Selective Detector attachment. The conversion of lactic acid and the selectivity toward acrylic acid or other by-products are calculated as follows with eqn (1) and (2), respectively.

$$
\begin{aligned}
& \text { Conversion } / \%=\frac{n_{0}-n_{1}}{n_{0}} \times 100, \\
& \text { Selectivity } / \%=\frac{n_{\mathrm{p}}}{n_{0}-n_{1}} \times 100
\end{aligned}
$$

where $n_{0}$ is the molar quantity of lactic acid fed into reactor, $n_{1}$ is the molar quantity of lactic acid in the effluent, and $n_{p}$ is the molar quantity of lactic acid converted to acrylic acid or other byproducts such as acetaldehyde, propionic acid, acetic acid, 2,3-pentanedione.

Area-specific catalytic rate is defined as previous references reported, ${ }^{22,28}$ and is determined with eqn (3) and (4).

LA consumption rate $=$

amount of LA consumed per hour in the reactor $\left(\mu \mathrm{mol} \mathrm{h} \mathrm{h}^{-1}\right)$ surface area of catalyst in the reactor $\left(\mathrm{m}^{2}\right)$

AA formation rate $=$ amount of AA formed per hour in the reactor $\left(\mu \mathrm{mol} \mathrm{h}{ }^{-1}\right)$ surface area of catalyst in the reactor $\left(\mathrm{m}^{2}\right)$

\section{Conclusions}

$\mathrm{BaSO}_{4}$ crystals with different defects were prepared by controlling the preparation conditions such as alkaline reagents, $\mathrm{pH}$ values and calcination temperature. It was found that these $\mathrm{BaSO}_{4}$ crystals with different defects offered different activities. Among the tested alkaline reagents, aqueous ammonia displayed an evidently promotional effect for dehydration of LA to AA since the $\mathrm{BaSO}_{4}$ crystal had an appropriate acid-base property caused by crystal defect. Besides, $\mathrm{pH}$ values and calcination temperature can also control the formation of crystal defect, which determined the acid-base property of catalyst. Relatively less acidity density and enhanced basicity density favored the dehydration of LA to AA. Under the optimal reaction conditions, the stability of $\mathrm{BaSO}_{4}$ catalyst treated with aqueous ammonia at $\mathrm{pH}=5$ was evaluated. Encouragingly, LA conversion reduced in $15 \%$ (from $100 \%$ to $85 \%$ ) within 28 h on stream.

\section{Conflicts of interest}

There are no conflicts to declare.

\section{Acknowledgements}

This work was supported by Sichuan Province Science and Technology Department application foundation project (2017JY0188), and the opening foundation of Jiangsu Key Laboratory of Vehicle Emissions Control (OVEC 032).

\section{Notes and references}

1 P. Maki-Arvela, I. L. Simakova, T. Salmi and D. Y. Murzin, Chem. Rev., 2014, 114, 1909-1971.

2 J. C. Serrano-Ruiz, R. Luque and A. Sepulveda-Escribano, Chem. Soc. Rev., 2011, 40, 5266-5281.

3 A. Corma, S. Iborra and A. Velty, Chem. Rev., 2007, 107, 24112502.

4 W. P. Deng, Y. Wang and N. Yan, Current Opinion in Green and Sustainable Chemistry, 2016, 2, 54-58.

5 S. Siankevich, S. Mozzettini, F. Bobbink, S. Ding, Z. Fei, N. Yan and P. J. Dyson, ChemPlusChem, DOI: 10.1002/ cplu.201700344.

6 G. Juodeikiene, D. Vidmantiene, L. Basinskiene, D. Cernauskas, E. Bartkiene and D. Cizeikiene, Catal. Today, 2015, 239, 11-16.

7 P. Wattanapaphawong, P. Reubroycharoen and A. Yamaguchi, RSC Adv., 2017, 7, 18561-18568.

8 Y. L. Wang, W. P. Deng, B. J. Wang, Q. H. Zhang, X. Y. Wan, Z. C. Tang, Y. Wang, C. Zhu, Z. X. Cao, G. C. Wang and H. L. Wan, Nat. Commun., 2013, 4, 2141.

9 C. Gao, C. Q. Ma and P. Xu, Biotechnol. Adv., 2011, 29, 930939.

10 I. Delidovich, P. J. C. Hausoul, L. Deng, R. Pfutzenreuter, M. Rose and R. Palkovits, Chem. Rev., 2016, 116, 1540-1599.

11 Y. M. Zhang, X. R. Chen, J. Q. Luo, B. K. Qi and Y. H. Wan, Bioresour. Technol., 2014, 158, 396-399. 
12 X. C. Wang, Y. L. Song, C. P. Huang, F. B. Liang and B. H. Chen, Green Chem., 2014, 16, 4234-4240.

13 L. D. Ye, X. D. Zhou, M. S. Bin Hudari, Z. Li and J. C. Wu, Bioresour. Technol., 2013, 132, 38-44.

14 C. A. Ramirez-Lopez, J. R. Ochoa-Gomez, M. FernandezSantos, O. Gomez-Jimenez-Aberasturi, A. Aonso-Vicario and J. Torrecilla-Soria, Ind. Eng. Chem. Res., 2010, 49, 6270-6278.

15 H. X. Yin, H. B. Yin, A. L. Wang, L. Q. Shen, Y. Liu and Y. Zheng, J. Nanosci. Nanotechnol., 2017, 17, 1255-1266.

16 G. Y. Yang, Y. H. Ke, H. F. Ren, C. L. Liu, R. Z. Yang and W. S. Dong, Chem. Eng. J., 2016, 283, 759-767.

17 B. Yan, L. Z. Tao, A. Mahmood, Y. Liang and B. Q. Xu, ACS Catal., 2017, 7, 538-550.

18 X. H. Zhang, L. Lin, T. Zhang, H. O. Liu and X. F. Zhang, Chem. Eng. J., 2016, 284, 934-941.

19 C. M. Tang, J. S. Peng, X. L. Li, Z. J. Zhai, W. Bai, N. Jiang, H. J. Gao and Y. W. Liao, Green Chem., 2015, 17, 1159-1166.

20 S. Lomate, T. Bonnotte, S. Paul, F. Dumeignil and B. Katryniok, J. Mol. Catal. A: Chem., 2013, 377, 123-128.

21 J. F. Zhang, J. P. Lin and P. L. Cen, Can. J. Chem. Eng., 2008, 86, 1047-1053.

22 J. F. Zhang, Y. L. Zhao, M. Pan, X. Z. Feng, W. J. Ji and C. T. Au, ACS Catal., 2011, 1, 32-41.

23 G. C. Gunter, D. J. Miller and J. E. Jackson, J. Catal., 1994, 148, 252-260.

24 M. S. Tam, J. E. Jackson and D. J. Miller, Ind. Eng. Chem. Res., 1999, 38, 3873-3877.

25 X. L. Li, L. W. Sun, W. X. Zou, P. Cao, Z. Chen, C. M. Tang and L. Dong, ChemCatChem, DOI: 10.1002/cctc.201701332.

26 L. W. Sun, X. L. Li and C. M. Tang, Acta Phys.-Chim. Sin., 2016, 32, 2327-2336.

27 M. E. Sad, L. F. González Peña, C. L. Padró and C. R. Apesteguía, Catal. Today, DOI: 10.1016/ j.cattod.2017.03.024.

28 C. M. Tang, Z. J. Zhai, X. L. Li, L. W. Sun and W. Bai, J. Catal., 2015, 329, 206-217.

29 C. M. Tang, Z. J. Zhai, X. L. Li, L. W. Sun and W. Bai, J. Taiwan Inst. Chem. Eng., 2016, 58, 97-106.

30 B. Katryniok, S. Paul and F. Dumeignil, Green Chem., 2010, 12, 1910-1913.

31 T. J. Korstanje, H. Kleijn, J. Jastrzebski and R. Gebbink, Green Chem., 2013, 15, 982-988.

32 X. L. Li, Z. J. Zhai, C. M. Tang, L. W. Sun, Y. Zhang and W. Bai, RSC Adv., 2016, 6, 62252-62262.

33 R. Beerthuis, G. Rothenberg and N. R. Shiju, Green Chem., 2015, 17, 1341-1361.
34 C. M. Tang, Y. Zeng, X. G. Yang, Y. C. Lei and G. Y. Wang, J. Mol. Catal. A: Chem., 2009, 314, 15-20.

35 B. Yan, L. Z. Tao, Y. Liang and B. Q. Xu, ACS Catal., 2014, 4, 1931-1943.

36 Y. Matsuura, A. Onda and K. Yanagisawa, Catal. Commun., 2014, 48, 5-10.

37 V. C. Ghantani, S. T. Lomate, M. K. Dongare and S. B. Umbarkar, Green Chem., 2013, 15, 1211-1217.

38 G. M. Lari, B. Puertolas, M. S. Frei, C. Mondelli and J. PerezRamirez, ChemCatChem, 2016, 8, 1507-1514.

39 C. Yuan, H. Y. Liu, Z. K. Zhang, H. F. Lu, Q. L. Zhu and Y. F. Chen, Chin. J. Catal., 2015, 36, 1861-1866.

40 J. F. Zhang, Y. L. Zhao, X. Z. Feng, M. Pan, J. Zhao, W. J. Ji and C. T. Au, Catal. Sci. Technol., 2014, 4, 1376-1385.

41 H. J. Wang, D. H. Yu, P. Sun, J. Yan, Y. Wang and H. Huang, Catal. Commun., 2008, 9, 1799-1803.

42 P. Sun, D. H. Yu, K. M. Fu, M. Y. Gu, Y. Wang, H. Huang and H. H. Ying, Catal. Commun., 2009, 10, 1345-1349.

43 J. S. Peng, X. L. Li, C. M. Tang and W. Bai, Green Chem., 2014, 16, 108-111.

44 C. M. Tang, J. S. Peng, G. Fan, X. L. Li, X. L. Pu and W. Bai, Catal. Commun., 2014, 43, 231-234.

45 C. M. Tang, J. S. Peng, X. L. Li, Z. J. Zhai, N. Jiang, W. Bai, H. J. Gao and Y. W. Liao, RSC Adv., 2014, 4, 28875-28882.

46 Z. Guo, D. S. Theng, K. Y. Tang, L. L. Zhang, L. Huang, A. Borgna and C. Wang, Phys. Chem. Chem. Phys., 2016, 18, 23746-23754.

47 S. Lyu and T. F. Wang, RSC Adv., 2017, 7, 10278-10286.

48 A. Linsebigler, G. Q. Lu and J. T. Yates, J. Chem. Phys., 1995, 103, 9438-9443.

49 G. Q. Lu, A. Linsebigler and J. T. Yates, J. Chem. Phys., 1995, 102, 3005-3008.

50 Y. Matsuura, A. Onda, S. Ogo and K. Yanagisawa, Catal. Today, 2014, 226, 192-197.

51 M. Behrens, F. Studt, I. Kasatkin, S. Kuhl, M. Havecker, F. Abild-Pedersen, S. Zander, F. Girgsdies, P. Kurr, B. L. Kniep, M. Tovar, R. W. Fischer, J. K. Norskov and R. Schlogl, Science, 2012, 336, 893-897.

52 C. Li, B. Wang, Q. Q. Zhu and T. W. Tan, Appl. Catal., A, 2014, 487, 219-225.

53 B. Wang, C. Li, Q. Q. Zhu and T. W. Tan, $R S C A d v ., 2014,4$, 45679-45686.

54 M. S. Holm, S. Saravanamurugan and E. Taarning, Science, 2010, 328, 602-605. 